\title{
ANÁLISIS
}

\section{José Martí, el océano Pacífico y la colonialidad global}

DOI: $10.32870 /$ mycp.v14i41.365

Woo, Suk Kyun ${ }^{1}$

\section{Resumen}

T osé Martí es considerado como héroe de la Independencia de Cuba así como un vidente que presagió la expansión imperialista de los Estados Unidos. Sin embargo, esta estimación no ha sido siempre positiva para la comprensión cabal de su pensamiento y trayectoria, puesto que se tiende a encerrarlo en el marco del Estado-nación o de América Latina (o en el mejor de los casos, en el marco del hemisferio occidental). Como Martí vivió una época de reconfiguración del mapa del imperialismo, en el que algunos países entraban en escena y otros se retiraban, sería necesario revisar un enfoque más amplio.

Bajo dicha premisa, este artículo intentará ubicar su tiempo y su vida en el contexto de una "globalización temprana", término utilizado por Benedict Anderson en su libro Bajo tres banderas: anarquismo e imaginación anticolonial (2005), para definir la situación mundial entre finales del siglo xIX y principios del xx. Revisaremos críticamente sus argumentos, siguiendo algunos conceptos de Walter Mignolo para definir ese tiempo como el de "colonialidad global”. Por último, enfocaremos algunas ideas de Martí sobre el racismo, un modo básico de operación de la colonialidad global.

Palabras clave: José Martí, océano Pacífico, colonialidad global, B. Anderson, W. Mignolo.

1. Profesor en el Instituto de Estudios Latinoamericanos en la Universidad Nacional de Seúl, Corea. Doctor en Literatura Hispanoamericana por la Universidad Complutense de Madrid. Correo electrónico: woosnuilas@gmail.com. Esta investigación fue financiada por el apoyo del proyecto HK (Korea Humanity Project) núm. KRF-2008-362-B00015. 


\section{Abstract}

José Martí is regarded as a hero of the independence of Cuba and a prophet who foretold the imperialist expansion of the United States. However, this estimate has not always been positive for the full understanding of his thought and career, since it tends to lock him within the frame of nationstate or Latin America (or at best, within the frame of Western Hemisphere). As Marti lived in the era of reconfiguration of the map of imperialism in which some countries came on stage and others were leaving, a more broad approach would be required. Under this premise, this article will attempt to locate his time and life in the context of "early globalization", a term used by Benedict Anderson in his book, Under Three Flags: Anarchism and Anti-Colonial Imagination (2005), to define the global situation between late nineteenth and early twentieth century. But this article will revise critically his arguments following some concepts of Walter Mignolo to define his time as an era of "global coloniality." Finally, this article will examine some ideas of Martí about the racism, a basic mode of operation of the global coloniality. Keywords: José Martí, Pacific Ocean, Global Coloniality, Benedict Anderson, Walter Mignolo.

\section{Introducción}

La vida de José Martí (1853-1895) fue ofrecida como un sacrificio total por la independencia de Cuba: fue preso político cuando apenas tenía 16 años, exiliado en varios países durante gran parte de su vida, fundador del periódico Patria y del Partido Revolucionario Cubano, que eran órganos centrales del movimiento independiente, propulsor y organizador del levantamiento armado así como su militante, etc. Su muerte es también muy conmovedora: habiendo recorrido el calvario, sucumbió en la primera batalla sin ver la patria libre que había esperado tanto toda la vida. No es nada sorprendente que Fidel Castro lo designara como "autor intelectual del 26 de julio"2 en el juicio del Moncada de 1953, y que luego lo convirtiera en una figura que simboliza el espíritu de la Revolución cubana. También para los disidentes, Martí es objeto

2. Castro, Fidel, "La historia me absolverá", 1953, en: http://bureau.comandantina.com/archivos/La\%20Historia\%20me\%20absolvera.pdf [consulta: 31 de marzo 2010]. 
de gran respeto, lo cual se detecta en el hecho de que una emisora anticastrista en Miami lleva su nombre, "Radio y Televisión Martí".

El respeto por Martí no es menor en América Latina en general. Y ello porque Martí elaboró un discurso de nacionalismo (pero aplicable a toda la región) en una época en que América Latina empezaba a necesitarlo por la creciente amenaza imperialista de Estados Unidos. Gracias a su experiencia vital en este país, Martí pudo captarla ya en los primeros años de la década de 1880, con más claridad y exactitud que sus contemporáneos. Por ejemplo, la celebración del primer Congreso Internacional de Washington en 1889, con la iniciativa de Estados Unidos de promover un vínculo más estrecho entre las dos Américas, significó para Martí que "ha[bía] llegado para la América española la hora de declarar su segunda independencia". ${ }^{3}$

Aun en el campo de batalla, Martí se preocupó no solamente por Cuba sino por los demás países latinoamericanos, lo cual se muestra nítidamente en su deseo de impedir a tiempo que "se extiendan por las Antillas los Estados Unidos y caigan, con esa fuerza más, sobre nuestra tierras de América”. ${ }^{4} \mathrm{Su}$ escrito más famoso, "Nuestra América" (1891), es una especie de cristalización de esta preocupación.

Sin embargo, el tiempo que le tocó a Martí corresponde a una era de mayor disputa por las nuevas colonias en la historia de los seres humanos, el cual conduciría finalmente a la I Guerra Mundial, como sabemos. El océano Pacífico no podía quedar libre de este contexto. Primero, la Primera Guerra del Opio (1840-1842) convierte a China (en aquel momento la dinastía Ching o Qing) en escenario de la competencia imperialista. En la segunda mitad del siglo XIX, esta disputa se extiende a otras áreas de Asia. El Reino Unido ocupa Birmania, y Francia la península indochina. La Alemania de Bismarck consigue colonias en el océano Pacífico. Rusia empieza a bajar hacia el sur buscando algún puerto libre de hielo. Japón crece y se convierte pronto en el único país imperialista no occidental. Es decir, una de las catacterísticas de este periodo es la incorporación de las nuevas potencias a la fila de los países imperialistas.

En cambio, hay países que se retiran de este escenario derrotados en la competencia, el ejemplo más representativo es la España de 1898 que perdió

3. José Martí, “Congreso internacional de Washington: su historia, sus elementos y sus tendencias", en José Martí, Nuestra América, Fundación Biblioteca Ayacucho, Caracas, 2005, p. 57 [Artículo publicado en La Nación, 19 de diciembre de 1889].

4. Martí, José, “Carta a Manuel Mercado”, en José Martí, Martí por Martí, Ed. Letras Cubanas, La Habana, 1982, p. 361 [Carta escrita entre el 18 y 19 de mayo de 1895]. 
Cuba, Puerto Rico, Filipinas y Guam, en total casi todas las últimas colonias que le quedaban. En esta coyuntura internacional, uno de los países más beneficiados fue Estados Unidos que obtuvo el control del mar Caribe con Cuba y Puerto Rico, y que consiguió un reducto importante en la expansión hacia Asia con Filipinas y Guam. Por lo tanto, para la comprensión cabal de la relación entre las dos Américas, es necesario tener en cuenta este cambio del contexto internacional. Además, hay que señalar el surgimiento de la nueva tendencia en la política colonialista que prefería sacar beneficios económicos a ocupar territorio para evitar enormes gastos y esfuerzos en su administración.

Es decir, el tiempo de Martí corresponde a la era de un nuevo diseño global que reconfiguraba el mapa mundial a gran escala en el proceso de competencia imperialista. Se diría que se trata de una "era de colonialidad global" en la que casi todas las regiones del mundo no podían escapar al avance del colonialismo de algunas potencias. Por todo lo antes expuesto, el objetivo del presente artículo es ubicar a Martí en este contexto de la colonialidad global para ofrecer una mayor comprensión sobre su tiempo y trayectoria.

\section{La globalización temprana a fines del siglo XIX}

En 1903, el presidente norteamericano Theodore Roosevelt se mandó a sí mismo un telegrama que dio una vuelta al mundo. El tiempo que se demoró fue apenas nueve minutos. Es una anécdota que aparece en Bajo tres banderas: anarquismo e imaginación anticolonial. Su autor, Benedict Anderson, la postula como una prueba de que a fines del siglo xix el mundo ya había entrado en una era de globalización temprana con muchos rasgos similares a la actual. Anderson destaca la creación de la Unión Postal Universal en 1876 y el desarrollo del transporte (barco de vapor, tren, etc.) como condiciones materiales necesarias de ese fenómeno, ya que posibilitaron la circulación de revistas, periódicos, fotografías y libros. Según Anderson, gracias a esta globalización temprana se hizo posible por primera vez en la historia una "coordinación transglobal" entre los anticolonialistas. Buscaban posibles alianzas transnacionales, intercambiaban opiniones e informaciones, se consultaban, aprendían el modo de lucha anticolonialista, etc. En este sentido, Anderson los considera como nómadas en la era de la globalización temprana. ${ }^{5}$

5. Anderson, Benedict, Bajo tres banderas: anarquismo e imaginación anticolonial, trad. Seo, Ji Won, Gil, Seúl, 2009 [1ª . ed. en inglés 2005], pp. 30-32. 
Para Anderson el ejemplo más ilustrativo es José Rizal (1861-1896). Este héroe filipino ha sido enfocado varias veces en la relación con José Martí. Por ejemplo, José María Laso Prieto enumera el paralelismo entre ambas personas: lucha anticolonial, prisión, estudios en España, obras literarias patrióticas, muerte temprana por la causa patriótica, la consagración posterior en su país, etc. ${ }^{6}$ Una diferencia importante es que Rizal no fue un independentista fehaciente. A diferencia de Martí, en su trayectoria a veces mostró vacilaciones inclinándose por el reformismo bajo el régimen colonial en vez de la revolución independentista. Pero si no le hubiera llegado la muerte tan tempranamente, hay mucha posibilidad de que habría optado finalmente por el camino a la independencia. De todas maneras, Rizal es uno de los nómadas tempranos según el concepto de Anderson, puesto que tenía informaciones sobre el movimiento independentista de Cuba y las actividades de Martí. Gracias a esta familiaridad, Rizal en su novela El filibusterismo (1891), toma a Cuba como uno de los escenarios importantes por donde pasa su personaje. Y él mismo, después de cuatro años bajo vigilancia durante el último momento de su vida, le pide permiso a la autoridad colonial para marchar a Cuba donde necesitaban a médicos como él debido al estallido de la guerra de la independencia en esta isla.

Un detalle más que me llama la atención en el libro de Anderson es el consejo que Ferdinand Blumentritt (1853-1913) le dio a Rizal. Blumentritt, natural del Imperio Austro-Húngaro, es un pro-filipinista que apoyaba su causa patriótica. El 30 de enero de 1892, le escribe a Rizal recomendándole que no declare la independencia de Filipinas sin considerar cuatro condiciones indispensables: 1. Una parte del ejército de España debería provocar disturbios contra su gobierno, 2. El fondo y las armas de las Filipinas deberían estar preparados suficientemente, 3. España debería estar en guerra con algún país, 4 . Debería haber país(es) que apoyara(n) abierta o sigilosamente la independencia de Filipinas. ${ }^{7}$ Cuando estalló la guerra en Cuba en 1895, los filipinos tuvieron un momento propicio porque España tenía que centrarse en el problema de Cuba por haber sido ésta una colonia mucho más importante económicamente. Pero Filipinas no llegó a lograr su independencia.

6. Laso Prieto, José María, "Paralelismo entre José Rizal, héroe nacional de Filipinas, y José Martí, héroe nacional de Cuba”, El Catoblepas, núm. 12, Nódulo Materialista, 2003, en: http:// www.nodulo.org/ec/2003/n012p06.htm [consulta: 24 de marzo 2011].

7. Anderson, Benedict, op. cit., pp. 194-195. 
Por supuesto que la posibilidad de las Filipinas no fue grande porque no disponían de las dos primeras condiciones indispensables. Además, el único país que hubiera podido apoyar era Estados Unidos. Pero como se constató unos años después, Estados Unidos no era un país aliado sino que entró en escena como nuevo dueño de Filipinas. Por lo tanto, Filipinas disponía solamente de una condición indispensable, con la cual era difícil esperar el éxito. Sin embargo, antes de señalar la inmadurez de la causa filipina, hay que destacar que tanto Cuba como Filipinas cayeron en manos de un país emergente con un afán igualmente imperialista. Bajo este contexto internacional, ¿podemos respaldar el punto de vista de Anderson que vio el embrión de las luchas anticoloniales entreconectadas a nivel mundial gracias a la globalización temprana?

Conviene considerar que Anderson pone cláusulas de reserva. Observa que Filipinas llamó la atención del mundo solamente en los años noventa del siglo XIX, ${ }^{8}$ que el levantamiento de Cuba en 1895 tuvo una repercusión pequeña en la historia turbulenta de la era de globalización temprana y que su culminación fue la i Guerra Mundial. Pese a estas reservas, el argumento de Anderson es difícil de aplicar al menos a las colonias de España. Lo que éstas realmente experimentaron fue el cambio del mando de España a Estados Unidos. ¿Cuál es la esencia de este cambio? El argumento de Robert J. C. Young es muy útil para aclararla. Young, ante todo, indica varios usos y confusiones de los términos "imperio, imperial e imperialismo". Luego, consultando a E. J. Hobsbawm, Winfried Baumgart y Raymond Williams, concluye que el término "imperialismo" fue empleado en dos sentidos por lo menos en el área de habla inglesa:

El término se ha utilizado en inglés predominantemente en dos sentidos. Originalmente constituía la descripción de un sistema político referido a la conquista real y a la ocupación. Pero desde principios del siglo xx, se utilizó cada vez más en su sentido marxista de un sistema general de la dominación económica, si es posible, con la dominación política directa, pero no necesariamente acompañado de ésta. ${ }^{9}$

8. Ibíd., p. 33.

9. Young, Robert J. C., Postcolonialism: An Historical Introduction, trad. Kim, Tack Hyun, Ed. Park Jong Chul, Seúl, 2005 [1 $1^{\text {a }}$. ed. en inglés 2001], p. 59. 
Young quería destacar la diferencia entre el imperialismo del siglo XIX protagonizado por el Reino Unido y Francia, y el del xx protagonizado por Estados Unidos. Aunque indica el siglo xx como comienzo del imperialismo de Estados Unidos, más adelante Young muestra que está tomando en cuenta los sucesos de $1898 .^{10}$

Young destaca un rasgo muy importante del imperialismo al afirmar que "el imperialismo fue siempre un producto de, y siempre dirigido a la política de potencia global". ${ }^{11} \mathrm{Y}$ desgraciadamente para los pueblos de las colonias, "el imperialismo surgió como la ideología de las clases gobernantes imperiales en el mismo periodo en que los primeros movimientos sustanciales de la libertad se desarrollaban en las colonias". ${ }^{12}$ Por eso es difícil considerar la globalización temprana como una época del auge de los movimientos anticoloniales interconectados a nivel global, como estima Anderson. Más bien, es la época de la apertura de un nuevo tipo de imperialismo a nivel global.

\section{El establecimiento de la estrategia global}

Según Peter H. Smith, autor de un libro con un amplio y profundo análisis sobre la relación entre América Latina y Estados Unidos, este país ya había entrado en la disputa imperialista prácticamente a fines del siglo XVIII. Es decir, apenas lograda su independencia en 1783. Para que los países latinoamericanos no fueran "eslabón frágil" en las amenazas intervencionistas de las potencias europeas, Estados Unidos quería que América Latina y sus recursos fueran exclusivamente destinados al beneficio de su país. ${ }^{13}$ Indudablemente la doctrina Monroe (1823), que constituía todavía una posición más bien defensiva, era la máxima expresión en esta actitud de Estados Unidos. Como se sabe, esta actitud defensiva se convierte en ofensiva con la tesis del "Destino Manifiesto”. Utilizada por el periodista estadounidense, John L. O’Sullivan, en un artículo publicado en 1845 en la revista Democratic Review, esta tesis fue tomada como una justificación en la anexión de Texas.

Pero a fines del siglo XIX, o sea en el tiempo de Martí, la política expansionista de Estados Unidos toma un rumbo diferente. No apunta a la adqui-

10. Ibíd, pp. 87-88.

11. Ibíd., p. 63.

12. Ídem.

13. Smith, Peter H., Talons of the Eagle: Latin America, the United States, and the World, $3^{\mathrm{a}}$. ed., Oxford University Press, Nueva York, 2008, pp. 18-19. 
sición de territorio como lo hizo con México sino a la creación de una esfera de interés, extendiendo la hegemonía de Estados Unidos a América Latina a través de una red informal de relaciones económicas y políticas. Smith explica que Estados Unidos intentó crear un imperio comercial. ${ }^{14}$

Para definir esta nueva tendencia del colonialismo, la teoría de la dependencia creó el concepto de "neocolonialismo". ${ }^{15}$ El giro del colonialismo al neocolonialismo por lo menos tiene dos motivos. Primero, la dominación directa no era un método eficiente. D. K. Fieldhouse demuestra que los imperios modernos no eran tan lucrativos económicamente. ${ }^{16}$ Incluso Inglaterra cayó en un dilema por los crecientes gastos administrativos y militares en India. Por eso, con Ching (o Qing) se limitó a la explotación económica. Segundo, estaba el problema del racismo. Según la perspectiva de los estadounidenses del siglo XIX, las razas de color no eran admisibles en su pueblo. Incluso había observaciones negativas en la anexión de Texas. Por otro lado, existía el miedo a lo sucedido en Haití en torno a su independencia. El que Cuba pudiera mantener su soberanía, aunque fuera afectada gravemente por la Enmienda Platt (1901), de alguna manera se debe a esta actitud excluyente de los estadounidenses. ${ }^{17}$

Sin embargo, con el concepto de neocolonialismo no se puede comprender la dimensión real del imperialismo de Estados Unidos. El paso del imperio clásico al imperio comercial no es un giro meramente de las políticas exteriores sino un producto de la estrategia global de Estados Unidos establecida en aquel momento. Tal vez la contradicción de James Blaine, el secretario de Estado de los Estados Unidos cuando se celebró la Primera Conferencia Panamericana en Washington entre 1889 y 1890, nos ayudaría a captar la existencia de la mencionada estrategia. El antecedente de esta conferencia es el histórico Congreso de Panamá convocado por Simón Bolívar en 1826. Pero mientras que el objetivo principal de éste era buscar una unidad política de América Latina, el de aquella era aumentar el comercio entre ambas Américas. James Blaine

14. Ibíd., pp. 27-28.

15. El hecho de que Martí fuera uno de los precursores de esta argumentación no pasó inadvertido. Por ejemplo, Juan Marinello señala la preocupación de Martí por el desbordamiento económico y la penetración del capitalismo financiero de los Estados Unidos. Véase Marinello, Juan, "Fuentes y raíces del pensamiento de José Martí", en José Martí, Nuestra América, Fundación Biblioteca Ayacucho, Caracas, 2005, p. XVIII.

16. D. K. Fieldhouse, citado por Robert J. C. Young, op. cit., p. 61.

17. Smith, Peter H., op. cit., pp. 51-54. 
fue el mismísmo impulsor de la Primera Conferencia Panamericana y en una afirmación de 1890 plantea que su país ya no busca expansión territorial sino el comercio. Pero al año siguiente escribe una carta al entonces presidente, Benjamin Harrison, enfatizando la necesidad de apoderarse de Cuba, Puerto Rico y Hawai. ${ }^{18}$ Esta sugerencia se hace realidad cuando Estados Unidos se anexiona Hawai en 1897, ocupa Puerto Rico y Filipinas después del triunfo sobre España en 1898 y le impone a Cuba la Enmienda Platt en 1901.

Esta anécdota se podría ver aparentemente como una contradicción entre dos políticas exteriores, entre dos imperialismos. Pero de ninguna manera existe tal contradicción. Simplemente, Estados Unidos tomó medidas convenientes en cada momento y éstas ya empezaron a operarse ateniéndose a una estrategia global del propio país. Cuando me refiero a la existencia de una estrategia global quiero decir que Estados Unidos llegó a tener una voluntad de dominar el mundo o, por lo menos, de proyectar su influencia en el mundo. Saco esta conclusión de la iniciativa de Alfred Thayer Mahan (1840-1914). Este hombre, que fue almirante, educador y estratega de Estados Unidos, planteó en La influencia del poder marítimo en la historia (1890) que el poder naval era la clave para que un país tuviera una influencia internacional. ${ }^{19}$ Este argumento, además de reconfirmar la necesidad de un canal en América Central, sugiere el dominio sobre ambos océanos, el Atlántico y el Pacífico. Por supuesto que esta propuesta es más bien una ansia colectiva de los estadounidenses por crecer como una potencia mundial desde mucho tiempo atrás. Por ejemplo, es bien sabido que la raíz del concepto de "Destino Manifiesto" es la creencia generalizada en amplios sectores de los estadounidenses de que su país está destinado a expandirse desde las costas del Atlántico a las del Pacífico. Pero la gran diferencia entre los años 1840 y los años 1890 es que Estados Unidos llegó a tener la capacidad suficiente de convertir su sueño de tipo etnocentrista en una realidad geopolítica. De todas maneras, con el control directo de Puerto Rico y el indirecto de Cuba, Estados Unidos estableció puntos estratégicos para dominar el Atlántico, mientras que Hawai, Guam y las Filipinas sirvieron como puntos estratégicos para dominar el Pacífico. Estos nuevos territorios serían las bases a partir de las cuales Estados Unidos planearía una estrategia global y realizaría el sueño de un imperio comercial. En fin,

18. Ward, Thomas, "Martí y Blaine: entre la colonialidad tenebrosa y la emancipación inalcanzable", Cuban Studies, núm. 38, Pittsburgh University Press, Pittsburg, 2007, p. 104.

19. Smith, Peter H., op. cit., p. 36. 
podemos argüir que el tiempo de Martí fue el origen de la estrategia global de Estados Unidos, cuya existencia real se hizo indiscutible después de la II Guerra Mundial hasta el presente.

La iniciativa de Alfred Thayer Mahan podía ser atractiva porque Estados Unidos necesitaba una rápida expansión en busca de mercados de exportación. Después de la Guerra Civil (1861-1865), la industrialización se aceleró en Estados Unidos y la economía se expandió a una velocidad vertiginosa. Sin embargo, sufrió tres depresiones por falta de consumidores a fines del siglo XIX: 1873-1878, 1882-1885 y 1893-1897. En 1899, el senador Albert J. Beveridge diagnosticó que como Estados Unidos producía más de lo que su pueblo consumía, debía encontrar nuevos mercados para la venta de los productos que sobraban, para la inversión del capital acumulado sin encontrar destinatarios, y para mantener sus trabajos. El año anterior, el Commercial Advertiser había mencionado la necesidad de hablar sobre una nueva Doctrina Monroe, cuya palabra clave debería ser la de política comercial, no de políticas internacionales como antes. ${ }^{20}$

En resumidas cuentas, la época de Martí corresponde al primer desarrollo de la estrategia global de Estados Unidos. Por lo tanto, es necesario calificar los méritos de Martí más allá del contexto del Estado-nación y del hemisferio occidental. Sin embargo, aunque se ponga atención en la política global de Estados Unidos y en su práctica e influencia en América Latina, todavía es necesario ampliar la perspectiva hasta la dimensión histórica, porque los pasos de Estados Unidos están en la prolongación de una colonialidad global a partir del siglo XVI. Desde esta perspectiva, otra vez se demostrará el límite del concepto de globalización temprana de Anderson y también el límite del concepto del neocolonialismo.

\section{La colonialidad global}

La entrada de Estados Unidos en el escenario del imperialismo no se debe simplemente a su origen mercantilista — como lo argumentaban Rubén Darío, José Enrique Rodó, etc.- , ni a su consecuente necesidad de una expansión ilimitada. Más bien, el transcurso de la historia de la modernidad —en realidad, me refiero a la historia de la modernidad-colonialidad como veremos más adelante- a partir del siglo XVI, de la que tantos pensadores y académi-

20. Ibíd., p. 29. 
cos querían desasirse vanamente desde fines del siglo $\mathrm{xx}$, ha movido hacia la consolidación de una colonialidad global.

Un artículo de Thomas Ward, un especialista en José Martí, cita (aunque sea de pasada) lo que quiero tomar como punto de partida en este capítulo: "[América Latina] Se pasa de la primera fase de la modernidad, encomenderos que vienen con la conquista, a lo que Mignolo llama la segunda fase de la modernidad, que bebe de las fuentes de la Ilustración, en la que los ejes ibéricos pierden sus posesiones al surgir las nuevas jerarquías". ${ }^{21}$

Quien hizo primero la distinción de dos modernidades y habló de la preexistencia de la primera modernidad ibérica del siglo XVI (concretamente el año 1492, es decir fines del siglo XV) al XVIII fue el filósofo argentino Enrique Dussel. ${ }^{22}$ Lo que los eurocentristas llaman la "modernidad" es para Dussel y también para Walter D. Mignolo la segunda modernidad que surgió en el Norte de Europa en el siglo XVIII. Partiendo de este planteamiento, Mignolo utiliza el término "diferencia imperial" para denominar la jerarquización de estas dos modernidades o la de los imperios: "Esta diferencia imperial es una diferencia entre imperios capitalistas, occidentales y cristianos; diferencia que encuentra en el conflicto entre protestantes en el norte y católicos en el sur la fuerza más contundente de la articulación de un nuevo imaginario occidentalista". ${ }^{23}$

Esta jerarquización ha sido tan consolidada que los triunfadores en la segunda modernidad llegaron a negar la existencia de la primera modernidad antecedente, tomando el siglo XVIII como punto de partida de la modernidad.

En el contexto latinoamericano, según Mignolo, esta diferencia imperial ya había comenzado en el siglo XVII con la "leyenda negra" y se extendía a lo largo del siglo XVIII:

La "leyenda negra" de la corrupción española, iniciada por los británicos para demonizar al Imperio Español como estratagema para dominar la economía del Atlántico en el siglo XVII, era parte de una lucha europea por las riquezas (en el sentido de acumulación y control del conocimiento, incluidos, por supuesto, la ciencia y la tecnología) económicas, políticas e intelectuales del "Nuevo Mundo".

21. Ward, Thomas, op. cit., p. 105.

22. Dussel, Enrique, 1492. El encubrimiento del otro, Antropos, Bogotá, pp. 33-34.

23. Mignolo, Walter D., Historias locales/diseños globales: Colonialidad, conocimientos subalternos y pensamiento fronterizo, trad. Juan María Madariaga y Cristina Vega Solís, Ediciones Akal, Madrid, 2003 [1 $1^{\text {a }}$ ed. en inglés 2000], p. 43. 
Así se origina la diferencia imperial que se extendería a lo largo del siglo XVIII y forjaría la concepción de "América Latina". ${ }^{24}$

La independencia de América Latina en la entrada al siglo XIX es una línea divisoria entre dos modernidades en este continente. España, además de que perdió su hegemonía salvo sobre unas islas del Caribe, fue señalada como culpable del subdesarrollo de América Latina. En cambio, el Reino Unido ejerció un control económico sobre este continente y Francia se convirtió en un modelo de civilización (recuérdese la dicotomía de Sarmiento, civilización y barbarie). El diseño global instalado posteriormente a la guerra entre España y Estados Unidos es igualmente importante porque es otro hito que marca la diferencia imperial. Ahora comienza la retirada de Inglaterra y el avance de Estados Unidos. Será un acto arriesgado si declaro a este hito como una línea divisoria entre la segunda modernidad y la tercera, modificando la tesis de dos modernidades de Dussel y Mignolo. ${ }^{25}$ Tampoco tengo la intención de abordar tal problema en este artículo. Pero, por lo menos, quiero señalar que Mignolo subraya que esa guerra es un hito tan importante como la Revolución francesa, con el argumento de que la distinción de América Anglosajona y América Latina fue establecida muy nítidamente. ${ }^{26}$

Como miembro del grupo de modernidad-colonialidad, Mignolo considera que la modernidad y la colonialidad son elementos constituyentes entre sí, es decir dos caras de una moneda (es la paráfrasis de la célebre frase, "el desarrollo y el subdesarrollo son las dos caras opuestas de la misma moneda", emitida por Andre Gunder Frank, uno de los precursores de la teoría

24. Mignolo, Walter D., La idea de América Latina: la herida colonial y la opción decolonial, trad. Silvia Jawerbaum y Julieta Barba, Gedisa, Barcelona, 2007 [1 $1^{\text {a }}$. ed. en inglés 2005], p. 79.

25. En cuanto a esta tesis de las dos modernidades, me gustaría citar una observación de mi colega coreano, el Dr. Kim, Jae Yong. Señalando el orgullo de China ante los europeos y el gran entusiasmo de Europa por China, Kim estima que entre el Renacimiento y la Primera Guerra del Opio el llamado eurocentrismo en realidad estaba limitado al nivel del etnocentrismo de los europeos. Para él, el triunfo del Reino Unido en la Guerra del Opio, la gran exposición internacional de Londres de 1851 en donde el Reino Unido mostró su potencia industrial, la estimación denigrativa de Marx en cuanto a China, etc., son el momento del triunfo del eurocentrismo sobre el mundo entero. Véase Kim, Jae Yong, "De la literatura mundial norteamericano-eurocéntrica a la literatura mundial global”, Silcheonmunhak, núm. 100, Silcheonmunhak, Seúl, 2010, pp. 28-42.

26. Delgado, L. Elena y Rolando J. Romero, "Local Histories and Global Designs: An Interview with Walter Mignolo", Discourse, vol. 22, núm. 3, Wayne State University Press, Detroit, 2000, p. 18. 
de la dependencia). Desde esta perspectiva, la historia moderna del mundo es la historia de la colonialidad planeada a nivel global. En este sentido, la irrupción de la segunda modernidad en América Latina protagonizada por Estados Unidos a fines del siglo xIX es la irrupción de la segunda colonialidad con una dimensión global.

\section{El racismo y Martí}

El acercamiento de Martí al problema de la raza es importante para comprender rasgos de Martí más allá del marco de Estado-nación y del hemisferio occidental. Para Mignolo, que revisa la distinción de América Anglosajona y América Latina en el contexto de la colonialidad global que se ha expandido a partir del siglo XVI, esta distinción está basada en el racismo. ${ }^{27}$ Esta perspectiva proviene originalmente de Aníbal Quijano, el sociólogo peruano y uno de los precursores del grupo. Y según éste y Mignolo, a pesar de que el racismo consigue una legitimidad "científica" en el siglo XVIII, sus raíces epistemológicas ya estaban establecidas en el XVI con la clasificación jerárquica que dividió la población mundial en diversas razas asignando a cada una un lugar. Ambos afirman que este acto de asignación es paralelo a la división internacional de la labor que ha sido requerida para la expansión del capitalismo en la sociedad moderna. ${ }^{28}$

En efecto, la emergencia de Estados Unidos en la jerarquía imperial reforzó el prejuicio racial. Como ya hemos señalado antes, Estados Unidos muchas veces vaciló en la anexión de territorio por el rechazo racial de su pueblo a las razas de color. Pero hemos visto que la intentó cuando fue conveniente para su estrategia global, sobre todo en la fase en que necesitaba andamios para el futuro dominio de los océanos Atlántico y Pacífico. Lo que hay que aclarar aquí es que también los estadounidenses tenían su propio pretexto para justificarla. Es decir, como "la evangelización" de los españoles, "la carga de los blancos" de los ingleses y "la misión civilizadora" de los franceses, los estadounidenses postulaban a su vez un credo. Si acudimos otra vez a Peter H. Smith, éste se inclina por "el evangelio de la democracia".

27. Ibíd., p. 18.

28. Castro Gómez, Santiago, "(Post)coloniality for Dummies: Latin American Perspectives on Modernity, Coloniality, and the Geopolitics of Knowledge", en Mabel Moraña, Enrique Dussel y Carlos A. Jáuregui, eds., Coloniality at Large: Latin America and the Postcolonial Debate, Duke University Press, Durham \& London, 2008, pp. 280-281. 
Al principio, este credo llevaba implícitamente el argumento de que Europa monárquica debía permanecer fuera del hemisferio occidental. Es decir, se trataba de otra expresión de la doctrina Monroe. Pero pronto se convertiría en una misión que Estados Unidos debía difundir en todo el mundo. ${ }^{29}$ En fin, la difusión del "evangelio de la democracia" es el producto del transcurso histórico del Occidente. De España a Estados Unidos no ha cambiado nada en el sentido de que han mantenido una actitud de ilustrar a la gente nooccidental. Y en realidad, esta actitud es una especie de disimulación de su proyecto colonizador.

Ahora habría que preguntarse qué pudo o intentó hacer Martí al hablar de la raza. Voy a tomar tres escritos para seguir brevemente sus ideas: "Madre América” (1889), "Nuestra América” (1891) y “Mi raza” (1893). A través del primero podemos captar su idea del nacionalismo (o latinoamericanismo). El título mismo sugiere una vinculación sanguínea entre América Latina y su gente; es un discurso lleno de frases de exaltación a las virtudes de América Latina. Habla de los latinoamericanos heroicos, trabajadores, francos y vigilantes que han construido una gran América Latina a partir del terreno estéril. ${ }^{30}$ Este tipo de nacionalismo es muy familiar, ya que la sublimación de la patria como objeto de veneración religiosa o su identificación con la madre (o padre) es un carácter típico del nacionalismo. Pero no era tan familiar para los latinoamericanos de aquella época.

Habría que pensar en la tesis de Sarmiento que insiste en la necesidad de importar la civilización europea para el desarrollo de Argentina (y América Latina). El caso de José Rizal es sugerente, ya que pese a ser reformista ha sido estimado como uno de los precursores que introdujo el nacionalismo en sentido moderno a Asia. Por ejemplo en China y Corea a fines del siglo XIX, es difícil encontrar a ideólogos del nacionalismo moderno comparables con Martí y Rizal.

En "Mi raza" podemos encontrar un afán similar. Mostrando aspectos nacionalistas, Martí otra vez demuestra un afán universalista:

El hombre no tiene ningún derecho especial porque pertenezca a una raza o a otra: dígase hombre, y ya se dicen todos los derechos. El negro, por negro, no

29. Smith, Peter H., op. cit., p. 43.

30. Martí, José, "Madre América”, en José Martí, Nuestra América, Losada, Buenos Aires, 1980, pp. 26-27 [Discurso pronunciado en la velada artístico-literaria de la Sociedad Literaria Hispanoamericana, en Nueva York, 19 de diciembre de 1889]. 
es inferior ni superior a ningún otro hombre; peca por redundante el blanco que dice: "Mi raza"; peca por redundante el negro que dice: "Mi raza". Todo lo que divide a los hombres, todo lo que especifica, aparta o acorrala es un pecado contra la humanidad". ${ }^{31}$

El argumento de Martí es nada menos que el concepto del derecho natural de los hombres, el eje central de las ideas de la Independencia de Estados Unidos y de la Revolución francesa. Según Anderson, esta preocupación por el universalismo seguramente le habrá ayudado mucho para reunir a sus compatriotas y al buscar apoyos de otras partes del mundo. Opina que el exitoso llamamiento de Martí al levantamiento armado fue gracias a su alejamiento de la cuestión racial aplacando el miedo difundido ante la posibilidad de que Cuba fuera un segundo Haití después de la independencia. ${ }^{32}$

En realidad, la aspiración universalista de Martí puede ser objeto de crítica por su ingenuidad simplista, ya que los problemas raciales internos de América Latina no han sido resueltos del todo hasta nuestros días. Incluso nos hace sospechar si Martí se daba cuenta del modo de operación de la colonialidad global basado en la jerarquía racial. Pero antes de pedirle una reflexión que va más allá de su tiempo - hay que recordar que en su época todavía no existían discursos bien planteados teórica ni lógicamente contra el racismo. Personalmente pienso que no es razonable pedirles a los ideólogos de la independencia un discurso antirracial antes de la aparición de Franz Fanon-, sería mejor revisar cuál es la virtud de Martí. A mi modo de ver, su virtud reside en el énfasis en la categoría del "hombre". En "Mi raza" dice: "hombre es más que blanco, más que mulato, más que negro". ${ }^{33}$ La categoría "hombre" por encima de la de "raza" sería la crítica de Martí al racismo de Estados Unidos y por lo tanto a la colonialidad global basada en el racismo. Es decir, Martí se apropió del discurso del derecho natural de los hombres del Occidente, utilizándolo criticó el racismo del Occidente y al fin cuestionó la lógica racial de la colonialidad global.

En este sentido, el planteamiento de "Nuestra América" merece una especial atención otra vez. La famosa frase, "no hay batalla entre la civilización y la

31. Martí, José, "Mi raza”, 1893, en: http://www.ensayistas.org/antologia/XIXA/marti/marti1. htm [consulta: 29 de marzo, 2011].

32. Anderson, Benedict, op. cit., pp. 215-6.

33. Martí, José, "Mi raza”, op. cit. 
barbarie, sino entre la falsa erudición y la naturaleza"34 muestra que Martí se dio cuenta exactamente de la misión de su época. En general, las interpretaciones atribuyen esta frase a una especie de nacionalismo cultural. Por ejemplo, Robert J. C. Young califica el intento de Martí como una perspectiva cultural de Calibán. ${ }^{35}$ Sin embargo, hay algo que este acercamiento no capta claramente.

Cuando Martí descarta la dicotomía civilización/barbarie, no está cuestionando solamente a Sarmiento sino el proyecto colonial entero del Occidente; y cuando descalifica el concepto de civilización atribuyéndolo a una

El intento de Martí es el cuestionamiento de la jerarquía colonial y la formación de un sujeto descolonial sin contaminación de los saberes occidentales falsa erudición, está cuestionando la colonialidad en el área del saber. De ninguna manera la categoría "nuestra América" es una operación simple de un nacionalismo defensivo basado en el orgullo cultural. El intento de Martí es el cuestionamiento de la jerarquía colonial y la formación de un sujeto descolonial sin contaminación de los saberes occidentales. A pesar de que acudió al discurso del Occidente, la crítica al racismo es una operación similar a la dicotomía falsa erudición/ naturaleza en el sentido de que indica la falsa erudición de los occidentales con respecto al problema de las razas.

\section{Conclusión}

En este artículo he criticado el concepto de globalización temprana de Benedict Anderson, he señalado el límite del concepto de neocolonialismo, he definido el tiempo de Martí como el de colonialidad global y he intentado una lectura (des)colonial de la época y del pensamiento de José Martí. Lo que queda claro es que Martí se equivocó al pensar, mirando la luz difusa, que por fin llegaría el alba. En realidad lo que estaba llegando detrás de esta luz era la noche larga. El destino de Cuba y América Latina se decidió en el proceso de la diferencia

34. Martí, José, "Nuestra América”, en José Martí, Nuestra América, Fundación Biblioteca Ayacucho, Caracas, 2005, p. 11.

35. Young, Robert J. C., op. cit., p. 369. 
imperial que acababa de comenzar en el contexto latinoamericano. No sé si abusé de la libertad de interpretación o no, aplicando una lectura (des)colonial a Martí. Sin duda, cada punto de vista construye su propio horizonte de interpretación, de manera que no podría insistir en que el mío sea la única verdad. Además, presenciamos una divergencia similar entre dos horizontes de interpretación en estos días. Me refiero al abismo que separa dos libros: Modernidad desbordada (1996) de Arjun Appadurai y Colonialidad desbordada (2008) editado por Mabel Moraña, Enrique Dussel y Carlos A. Jáuregui. Mientras que el primero habla de una modernidad global, el segundo se refiere a una colonialidad global. Frente a esta discrepancia, es difícil estimar que un libro tenga razón exclusivamente y el otro no. Para afirmarlo, sería necesario un argumento muy sólido y coherente. Pese a este entendimiento, me he aventurado a postular el concepto de colonialidad global rechazando el concepto de globalización temprana de Anderson. Y esto es porque, desde mi punto de vista, la emergencia de Estados Unidos como un imperio global es un factor mucho más importante que el incipiente intento de la solidaridad y actividad transglobales para aclarar la situación de Cuba, del hemisferio occidental y del mundo entero. my

\section{Bibliografía}

Anderson, Benedict, Bajo tres banderas: anarquismo e imaginación anticolonial, trad. Seo, Ji Won. Gil, Seúl, 2009 [1ª . ed. en inglés 2005].

Castro, Fidel, "La historia me absolverá", 1953, en: http://bureau.comandantina.com/archivos/La\%20Historia\%20me\%20absolvera.pdf [consulta: 31 de marzo 2010].

Delgado, L. Elena y Rolando J. Romero, "Local Histories and Global Designs: An Interview with Walter Mignolo", Discourse, vol. 22, núm. 3, Wayne State University Press, Detroit, 2000, pp. 7-33.

Dussel, Enrique, 1492. El encubrimiento del otro, Antropos, Bogotá, 1992.

Kim, Jae Yong, "De la literatura mundial norteamericano-eurocéntrica a la literatura mundial global”, Silcheonmunhak, núm. 100, Silcheonmunhak, Seúl, 2010, pp. 28-42.

Laso Prieto, José María, "Paralelismo entre José Rizal, héroe nacional de Filipinas, y José Martí, héroe nacional de Cuba”, El Catoblepas, núm. 12, Nódulo Materialista, http://www.nodulo.org/ec/2003/n012p06.htm, 2003 [consulta: 24 de marzo 2011]. 
Martí, José, Martí por Martí, Ed. Letras Cubanas, La Habana, 1982.

—_, "Mi raza", 1893, en: http://www.ensayistas.org/antologia/XIXA/marti/ marti1.htm, [Consulta: 29 de marzo, 2011].

- - "Madre América", en José Martí, Nuestra América, Losada, Buenos Aires, 1980, pp. 26-27.

—- Nuestra América, Fundación Biblioteca Ayacucho, Caracas, 2005.

Mignolo, Walter D., Historias locales/diseños globales: Colonialidad, conocimientos subalternos y pensamiento fronterizo, trad. Juan María Madariaga y Cristina Vega Solís, Ediciones Akal, Madrid, 2003 [1 $1^{\text {a }}$. ed. en inglés 2000].

- - La idea de América Latina: la herida colonial y la opción decolonial, trad. Silvia Jawerbaum y Julieta Barba. Gedisa, Barcelona, 2007 [1 ${ }^{\mathrm{a}}$. ed. en inglés 2005].

Moraña, Mabel, Enrique Dussel y Carlos A. Jáuregui, eds., Coloniality at Large: Latin America and the Postcolonial Debate, Duke University Press, Durham y Londres, 2008.

Smith, Peter H., Talons of the Eagle: Latin America, the United States, and the World, $3^{\mathrm{a}}$. ed., Oxford University Press, Nueva York, 2008.

Ward, Thomas, "Martí y Blaine: entre la colonialidad tenebrosa y la emancipación inalcanzable", Cuban Studies, núm. 38, University of Pittsburgh Press, Pittsburgh, 2007, pp. 100-124.

Young, Robert J. C., Postcolonialism: An Historical Introduction, trad. Kim, Tack Hyun. Ed. Park Jong Chul, Seúl, 2005 [1ª. ed. en inglés 2001]. 